\title{
Effect of the Amount of Pt Loading on the Oxygen Storage Capacity of Ceria-Zirconia Solid Solution
}

\author{
Akihiko SUDA, Kae YAMAMURA, Hideo SOBUKAWA, Yoshio UKYO, Toshitaka TANABE, \\ Yasutaka NAGAI, Fei DONG and Masahiro SUGIURA \\ Applied Catalysis Lab., TOYOTA Central R\&D Labs., Inc., Nagakute, Aichi 480-1192
}

\author{
白金/セリア-ジルコニア固溶体の酸素貯蔵能に及ぼす白金担持量の影響 \\ 須田明彦 · 山村佳恵 ·曽布川英夫 ·右京良雄 ·田辺稔貴 ·長井康貴 ·董＼cjkstart飛·杉浦正洽 \\ (株) 豊田中央研究所触媒研究室，480-1192 愛知県長久手町
}

\begin{abstract}
As an important oxygen storage material, ceria-zirconia solid solution is widely used in automotive three-way catalysts. For the $\mathrm{Ce}-\mathrm{Zr}$ solid solution being usually used with a noble metal, the evaluation of oxygen storage capacity (OSC) should be conducted with the $\mathrm{Ce}-\mathrm{Zr}$ solid solution loaded with a noble metal. The measured OSC of noble-metal-loaded Ce-Zr solid solution consists of two parts: the stored oxygen within the solid solution itself and the adsorbed oxygen on the loaded noble metal particles. Therefore, it is very necessary to clarify the influence of metal loading on the measured OSC in order to ascertain the exact OSC of the solid solution itself. In this research, the authors attempted to clarify the above issues by characterizing the OSC performance of Ce-Zr solid solutions with platinum (Pt) loading from 0.0001-10 mass \%. We found that increasing the amount of Pt loading increases the oxygen storage and release rates and that increasing the temperature also increases the oxygen storage rate, although the oxygen release rate is not affected by increasing the temperature. The apparent OSC reached saturation over a certain amount of Pt loading and temperature. The saturated OSC increased with increasing temperature.

[Received May 6, 2004; Accepted September 22, 2004]
\end{abstract}

Key-words : Ceria-zirconia solid solution, Oxygen storage capacity (OSC), Pt loading, Automotive exhaust catalyst, Redox reaction

1. Introduction

Ceria-zirconia solid solution is widely used in three-way catalysts for most gasoline vehicles. Through oxygen storage/ release using the ceria-zirconia solid solution, a buffer between lean-rich swings in an exhaust gas composition during vehicle operation is obtained for maintaining a stoichiometric atmosphere, so that $\mathrm{HC}, \mathrm{CO}$ and $\mathrm{NO}_{\mathrm{x}}$ are efficiently converted. The oxygen storage capacity (OSC) of an oxygen storage material dominantly affects the performance of a three-way catalyst. ${ }^{1), 2)}$ To improve the OSC, numerous research studies were performed to dissolve zirconia into the lattice of ceria beyond the solid solubility limit. ${ }^{3)-13)}$ More stringent environment regulations are going to be imposed on the automotive industry in the near future, thus a next-generation three-way catalyst with a superior performance is eagerly being expected. Improving the OSC of an oxygen storage material is an important approach for developing a more efficient automotive three-way catalyst. Recently, ceria-zirconia solid solution containing a high amount of zirconia has been predominantly used as an oxygen storage material for a three-way catalyst. For the development of better oxygen storage materials, a reasonable estimation of the OSC, a correct interpretation of the OSC performance, and a deep understanding or knowledge of oxygen storage materials are very necessary, particularly the OSC under a practical reaction condition.

OSC is usually measured in an oxygen storage material without active sites, for example, without noble metals loaded, and the saturation of OSC at a certain temperature is also scarcely discussed. For the estimation of the actual OSC performance, and for further development of a better oxygen storage material, it is very important to comprehend the saturation of OSC and the role or influence of the active sites, the loaded noble metals.

The OSC of several ceria-zirconia solid solutions loaded with 1 mass $\%$ platinum $(\mathrm{Pt})$ were reported in a previous paper. ${ }^{11)}$ The oxygen release rates of these ceria-zirconia solid solutions were enhanced largely by loading Pt under a reductive atmosphere. ${ }^{11)}$ It is well known that all automotive threeway catalysts are loaded with precious metals. How much is exactly the influence of the loaded metal on the OSC, and how does this metal affect the OSC? Unfortunately, no data or information are available from the published literatures thus far. These data or information are very important for estimating the actual OSC performance, related closely with the catalyst formulation and the cutting down of the catalyst cost. In this research, for this purpose, we loaded $\mathrm{Pt}$ on the ceria-zirconia solid solution from 0.0001 to 10.0 mass $\%$, and studied the influence of Pt loading on the OSC performance.

\section{Experimental}

\subsection{Catalyst preparation}

The aqueous solution with the same molar concentrations of cerium nitrate and zirconium oxynitrate was used as starting material. Precipitation was achieved by modifying the $\mathrm{pH}$ value with ammonia solution. After calcination for $5 \mathrm{~h}$ at $500^{\circ} \mathrm{C}$, the ceria-zirconia solid solution containing $50 \mathrm{~mol} \%$ ceria and $50 \mathrm{~mol} \%$ zirconia was synthesized. Pt was loaded from 0.0001 to 10.0 mass \% into the ceria-zirconia solid solution by the impregnation method, using diluted nitric acid solution of $\mathrm{Pt}\left(\mathrm{NH}_{3}\right)_{2}\left(\mathrm{NO}_{2}\right)_{2}$ as the $\mathrm{Pt}$ precursor. The Ptloaded solid solutions were calcined again at $500^{\circ} \mathrm{C}$ for $3 \mathrm{~h}$ in air after impregnation. 


\subsection{Measurement of OSC and oxygen storage and} release rates

OSC was measured by the thermo-gravimetric (TG) method. About $15 \mathrm{mg}$ of the Pt-loaded solid solution was set up on a thermogravimeter (Shimadzu TGA-50). The catalyst was first pretreated or pre-oxidized at $500^{\circ} \mathrm{C}$ for $2 \mathrm{~h}$ with $29 \% \mathrm{O}_{2}\left(\mathrm{~N}_{2}\right.$-balanced), and then reduced and oxidized repeatedly for several times at an adsorption time of $5 \mathrm{~min}$. The measurement temperature ranged from 50 to $500^{\circ} \mathrm{C}$. The weight loss and gain obtained using the thermogravimeter upon reduction and oxidation was taken as the OSC. The reductive and oxidative atmospheres were $17 \% \quad \mathrm{H}_{2} \quad\left(\mathrm{~N}_{2-}\right.$ balanced $)$ and $29 \% \mathrm{O}_{2}\left(\mathrm{~N}_{2}\right.$-balanced $)$, respectively. The OSC calculated from the weight change was called the apparent OSC. Oxygen storage and release rates were calculated from the slope of the oxidation and reduction profiles obtained using the thermogravimeter.

\subsection{Measurement of $\mathrm{Pt}$ dispersion}

Pt dispersion was analyzed by chemical adsorption on a flow-type adsorption apparatus using $\mathrm{CO}$ pulse gas (OHKURA RIKEN R-6015). Pt dispersion ( $D$, the percentage of $\mathrm{Pt}$ atoms exposed on the surface) and $\mathrm{Pt}$ particle size $\left(d_{\mathrm{p}}\right)$ were derived from the chemisorbed CO amount, assuming that $\mathrm{CO}$ stoichiometrically adsorbs on the spherical $\mathrm{Pt}$ particles at $\mathrm{CO} /$ surface $\mathrm{Pt}=1: 1$.

\subsection{Temperature-programmed reduction}

Temperature-programmed reduction (TPR) experiments were conducted using two kinds of catalyst. One catalyst was 1.0 mass\% Pt-loaded ceria-zirconia solid solution with a Ce/ $\mathrm{Zr}$ molar ratio of $5: 1$. The other catalyst was 1.0 mass $\% \mathrm{Pt}-$ loaded gamma-alumina $\left(\gamma-\mathrm{Al}_{2} \mathrm{O}_{3}\right)$. The loaded $\mathrm{Pt}$ was the same as that in Section 2.1. Both catalysts were first heated up to $500{ }^{\circ} \mathrm{C}$ in $10 \%$ of $\mathrm{O}_{2}$ (Ar-balanced), and then cooled down to $-70^{\circ} \mathrm{C}$. After the system got stable, $1 \% \mathrm{H}_{2}$ (Ar-balanced) gas was introduced and $\mathrm{H}_{2}$ uptake was detected using a TCD detector while increasing the temperature at a rate of $100^{\circ} \mathrm{C} /$ minute. A lot of $\mathrm{H}_{2}$ consumption against the temperature indicated the oxygen release from each catalyst at a certain temperature, which corresponds to the redox property of them.

\section{Results and discussion}

3.1 Relationship between amount of Pt loading and OSC

Figure 1 shows the examples of the weight change during oxidation and reduction (OSC measurement). The relationship between the amount of Pt loading and the apparent OSC of the ceria-zirconia solid solution is plotted against the measured temperature in Fig. 2. The apparent OSC increased with the amount of Pt loading and the temperature. These tendencies could be due to the following three factors: the increase of oxygen adsorption on the surface of loaded Pt particles with increasing amount of Pt loading, the enhancement of oxygen storage/release of the ceria-zirconia solid solution by the loaded Pt, and the enhancement of nonstoichometric oxygen adsorption by increasing the temperature. The third factor corresponds to the intrinsic OSC of the ceria-zirconia solid solution. If the contributions of these three factors could be separated, the phenomenon of oxygen storage/release could be understood deeply and clearly.

3.2 TPR study on Pt loaded catalysts

The TPR profiles of Pt-loaded/ceria-zirconia solid solutions and Pt-loaded/gamma-alumina are shown in Fig. 3. The decrease in the amount of $\mathrm{H}_{2}$ indicates that oxygen is released from the catalysts. The sharp and long-tailed TPR peak at a low temperature for Pt-loaded/gamma-alumina corresponds to the release of the oxygen atoms adsorbed on the Pt surface,
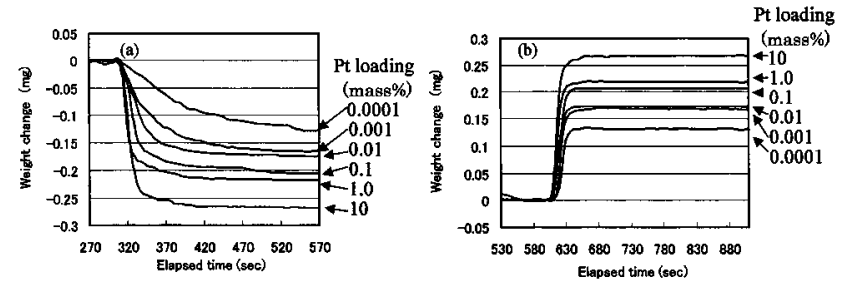

Fig. 1. Weight change during oxidation and reduction of ceriazirconia solid solution with Pt loading measured at $500^{\circ} \mathrm{C}$.

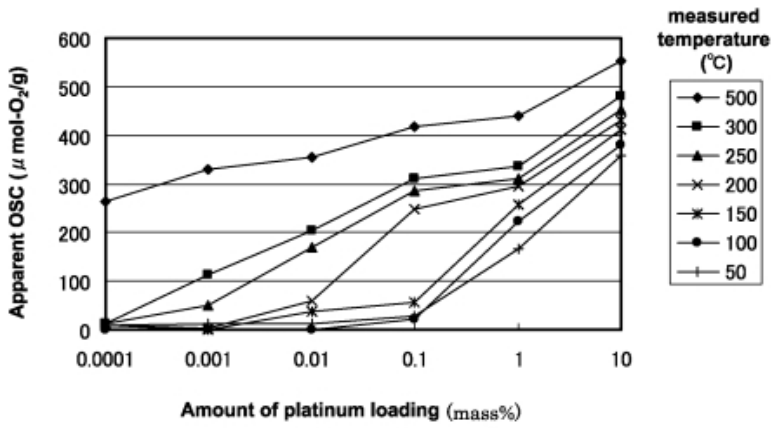

Fig. 2. Apparent OSC of ceria-zirconia solid solution with Pt loading at various temperatures. OSC: oxygen storage capacity.

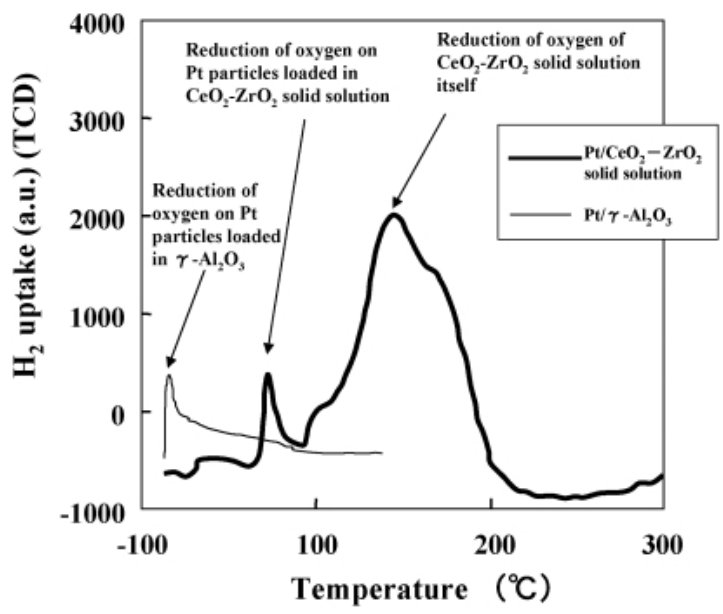

Fig. 3. TPR curves of Pt-loaded ceria-zirconia solid solution and Pt-loaded gamma-alumina.

because oxygen atoms could only adsorb on Pt particles on the catalyst. Two peaks are observed in the TPR curve of the Ptloaded/ceria-zirconia solid solution. The first peak (at a low temperature) could be ascribed to the oxygen adsorbed on the Pt surface, because the shape of the first peak is similar to that of Pt-loaded/gamma-alumina. The second peak has a relatively broad and dull shape, and locates at a higher temperature, indicating the release of oxygen from the crystal lattice of the ceria-zirconia solid solution. The oxygen can be released from the surface of the Pt particles in the ceria-zirconia solid solution even at a low temperature of $50^{\circ} \mathrm{C}$. The difference in oxygen removal temperature of the two catalysts comes from the significant difference of an electronic state of Pt between in a gamma-alumina and in a ceria-zirconia solid solution. 


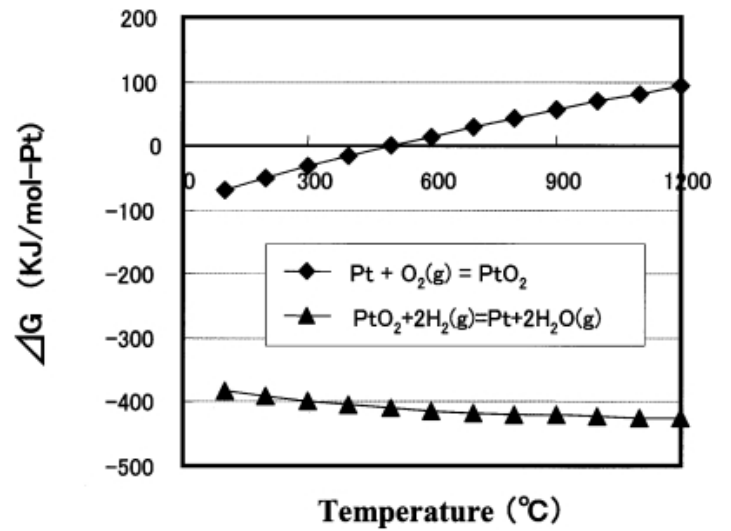

Fig. 4. Gibbs free energy change upon the reactions of $\mathrm{Pt}$ with $\mathrm{O}_{2}$ and $\mathrm{PtO}_{2}$ with $\mathrm{H}_{2}$ (these data were calculated by HSC Chemistry for Windows: thermochemical database, Outokump).

\subsection{Free energy change along with the redox reaction on} $\mathrm{Pt}$

Gibbs free energy changes upon the reactions of $\mathrm{Pt}$ with $\mathrm{O}_{2}$ and $\mathrm{PtO}_{2}$ with $\mathrm{H}_{2}$ are shown in Fig. 4. The calculation results show that $\mathrm{Pt}$ tends to be oxidized to form $\mathrm{PtO}_{2}$ at a temperature lower than $500^{\circ} \mathrm{C}$ under an oxidative atmosphere. $\mathrm{PtO}_{2}$ tends to be reduced back to its metallic form over a temperature range under a reductive atmosphere. Therefore, the results in Fig. 3 and the calculated results in Fig. 4 indicate that the redox reaction of $\mathrm{Pt}$ has an influence on OSC in the entire temperature range in Fig. 1. If the amount of adsorbed oxygen on the Pt particles is known, we can estimate the intrinsic OSC of ceria-zirconia solid solution itself.

3.4 Relationship between amount of Pt loading and Pt dispersion in a ceria-zirconia solid solution

The specific surface area, average particle size and dispersion of the Pt particles are tabulated against the amount of $\mathrm{Pt}$ loading into the ceria-zirconia solid solution in Table 1. Figure 5 shows the relationship between the amount of $\mathrm{Pt}$ loading and Pt dispersion in the ceria-zirconia solid solution with a regression curve. The $\mathrm{Pt}$ dispersion decreases with increasing loading amount. A regression coefficient, $R^{2}=$ 0.9969 , indicates a good approximation based on the formula in Fig. 5. Because the Pt dispersion with the loading amount lower than 0.01 mass \% was unreliable, it could be estimated by extrapolation using the regression formula. The $\mathrm{Pt}$ dispersion values are $73.7 \%$ at the Pt loading of 0.01 mass $\%$ and 73.8\% at the Pt loading less than 0.001 mass \%.

3.5 Estimation of amount of oxygen atoms adsorbed on Pt particles

First, one oxygen molecule is assumed to adsorb on the surface of the Pt at a constant rate, similarly to one $\mathrm{CO}$ molecule. With this assumption, oxygen adsorption could be estimated by multiplying the total amount (mol) of Pt loading by Pt dispersion. If the adsorption rate of oxygen is assumed to be the same as that of $\mathrm{CO}$, the amounts of oxygen adsorption should be $0.004,0.04,0.4,3.8,33.4$ and $140.4 \mu \mathrm{mol}-\mathrm{O}_{2}$ per gram of catalyst, corresponding to the the amount of Pt loading of $0.0001,0.001,0.01,01,1$ and 10 mass \%, respectively. On the other hand, the authors reported that the OSC of 1 mass $\% \mathrm{Pt}$ loaded ceria-zirconia solid solution measured using the same condition as this experiment is equivalent to that of the ceria-zirconia solid solution without $\mathrm{Pt}$ loading reduced for $2 \mathrm{~h}$ at $500^{\circ} \mathrm{C} .{ }^{11)}$ Therefore, the intrinsic OSC of the ceria-zirconia solid solution is thought to be reasonably measured with
Table 1. Relationship between Amount of Pt Loading and $\mathrm{Pt}$ Dispersion in Ceria-Zirconia Solid Solution

\begin{tabular}{lcccccc}
\hline Amount of Pt loading (mass\%) & 0.1 & 1 & 2 & 3 & 5 & 10 \\
Specific surface area of $\mathrm{Pt}\left(\mathrm{m}^{2} / \mathrm{g}\right)$ & 0.35 & 3.1 & 5.8 & 7.7 & 10.5 & 13 \\
Average particle size of $\mathrm{Pt}(\mathrm{nm})$ & 0.67 & 0.75 & 0.8 & 0.91 & 1.11 & 1.79 \\
Pt dispersion (\%) & 73.5 & 65.3 & 61.5 & 53.7 & 44 & 27.4 \\
\hline
\end{tabular}

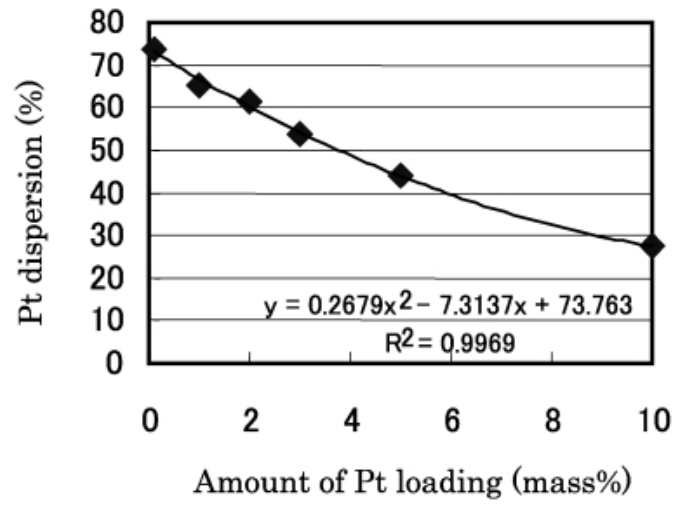

Fig. 5. Relationship between amount of Pt loading and Pt dispersion in ceria-zirconia solid solution. A regression curve is also shown.

Table 2. Oxygen Adsorption Amount on Loaded Pt

\begin{tabular}{|c|c|c|c|c|c|c|}
\hline Amount of Pt loading (mass\%) & 0.0001 & 0.001 & 0.01 & 0.1 & 1 & 10 \\
\hline $\begin{array}{l}\text { Oxygen adsorption amount } \\
\text { on loaded } \mathrm{Pt}\left(\mu \mathrm{mol}-\mathrm{O}_{2} / \mathrm{g} \text {-catalyst }\right)\end{array}$ & 0.0056 & 0.056 & 0.56 & 5.3 & 46.4 & 195 \\
\hline
\end{tabular}

1 mass \% Pt loading at $500^{\circ} \mathrm{C}$. Based on this result, the OSC difference between the 1 mass $\%$ and 10 mass \% Pt loading samples comes from the adsorbed oxygen on the excess $\mathrm{Pt}$ surface of the 10 mass \% Pt loading sample. The specific $\mathrm{Pt}$ surface area of $\mathrm{Pt}$ of the 10 mass\% $\mathrm{Pt}$ loading sample is 10 $\mathrm{m}^{2} / \mathrm{g}$ larger than that of 1 mass $\% \mathrm{Pt}$ loading sample. The weight difference of ceria-zirconia solid solution itself of both samples must also be compensated. Based on the above-mentioned assumption, the amount of oxygen molecules adsorbed on the Pt surface is 1.39 times per unit surface area which is larger than that of $\mathrm{CO}$ molecules. The oxygen adsorption amount on the Pt particles is listed in Table 2.

The values in Table 2 subtracted from the data in Fig. 1 represent the OSC of ceria-zirconia solid solution itself, which is shown in Fig. 6. The increasing tendency of OSC values recedes and seems to reach saturation at 0.1 mass\% $\mathrm{Pt}$ loading at higher than $200^{\circ} \mathrm{C}$. The OSC values measured at 100 and $150^{\circ} \mathrm{C}$ seem to recede at 1 mass\% $\mathrm{Pt}$ loading.

3.6 Effect of Pt loading on oxygen storage and release rates

The oxygen storage and release rates of the Pt loaded ceria-zirconia solid solution were determined from the slope of the oxidation and reduction profiles obtained using the thermogravimeter, as shown in Figs. 7 and 8. The oxygen storage rate increases with increasing temperature and amount of Pt loading. The oxygen release rate also increases with $\mathrm{Pt}$ loading; however, it is only slightly affected by the temperature. The storage and release rates are almost the same at $250^{\circ} \mathrm{C}$. The storage rate is smaller than the release rate at a 


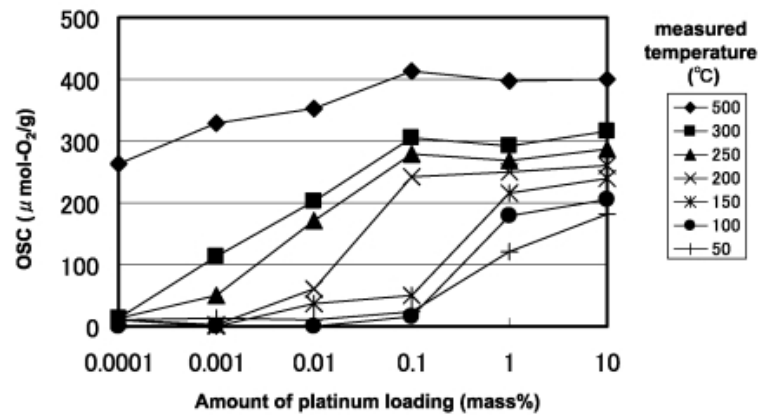

Fig. 6. OSC of ceria-zirconia solid solution itself (intrinsic OSC). These data were derived by subtraction of the amount of adsorbed oxygen on Pt from the apparent OSC data in Fig. 1.

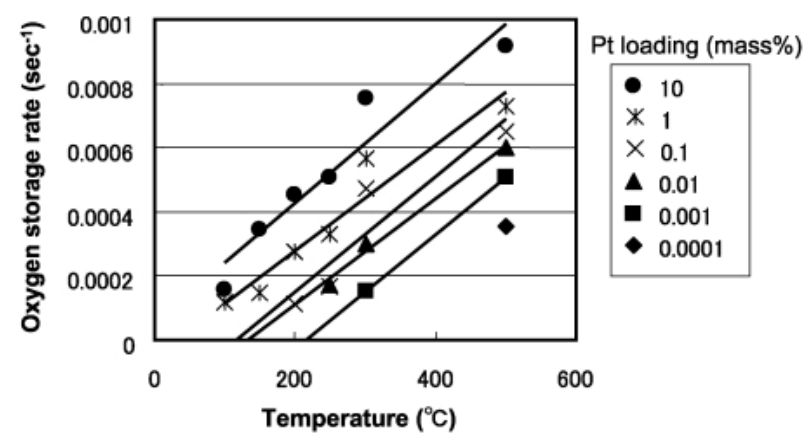

Fig. 7. Oxygen storage rate of ceria-zirconia solid solution with $\mathrm{Pt}$ loading in oxidative atmosphere at various temperatures.

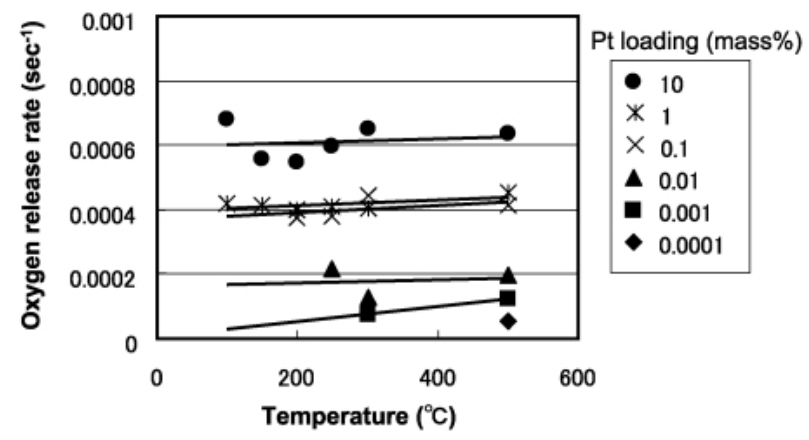

Fig. 8. Oxygen release rate of ceria-zirconia solid solution with $\mathrm{Pt}$ loading in oxidative atmosphere at various temperatures.

temperature lower than $200^{\circ} \mathrm{C}$. The result that the amount of $\mathrm{Pt}$ loading influences both the storage and release processes indicates that oxygen or hydrogen goes through the Pt particles in the oxygen storage or release process. However, the storage process without $\mathrm{Pt}$ loading also has a considerable rate at $500^{\circ} \mathrm{C},{ }^{11)}$ indicating that the storage process has an oxidation route even without $\mathrm{Pt}$. The temperature dependence of the storage rate is stronger than that of the release rate. This phenomenon comes from the direct oxidation in the storage process. Further studies will be necessary for more profound understanding about the oxygen storage and release processes of Pt-loaded ceria-zirconia solid solution. For example, using reductive agents other than hydrogen, other types of reactor for reducing the reaction time and more sensitive and more

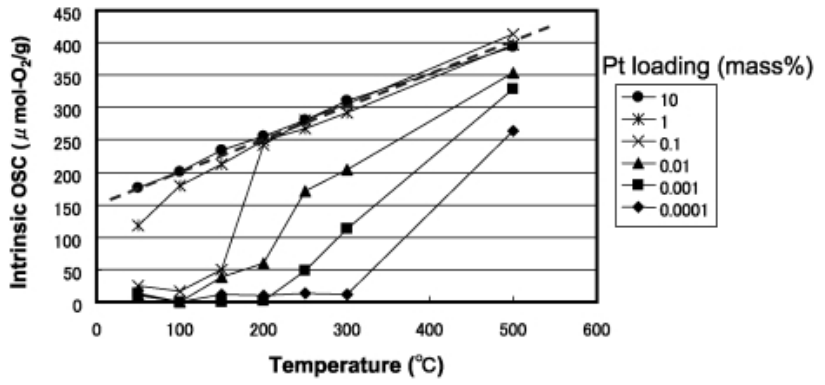

Fig. 9. Intrinsic OSC of ceria-zirconia solid solution against temperature. The dashed line indicates the maximum OSC of the ceria-zirconia solid solution under the condition used in this study.

reliable methods of detecting reduction and oxidation should be necessary for further studies.

The curves in Fig. 9 are plotted against the temperature instead of the amount of Pt loading as in Fig. 6. The dashed line indicates the maximum OSC at each temperature under the conditions used in this study. The reason why the data are away from the dashed line is that the restricted oxygen release or storage rate is very low to release adsorbed oxygen completely at 300 and $500^{\circ} \mathrm{C}$ or very low to store oxygen completely at a temperature under $250^{\circ} \mathrm{C}$ within $5 \mathrm{~min}$.

\section{Conclusions}

To clarify the influence of the loaded Pt on the OSC of ceria-zirconia solid solution itself, the OSC of ceria-zirconia solid solution with Pt loading from 0.0001 to 10 mass\% was studied at temperatures from 50 to $500^{\circ} \mathrm{C}$. The following conclusions were drawn.

(1) The OSC of the Pt-loaded ceria-zirconia solid solution is the sum of the OSC of the ceria-zirconia solid solution itself and the oxygen adsorbed on the surface of the loaded Pt particles.

(2) The amount of oxygen adsorbed on the Pt surface is approximately 1.4 times larger than that of $\mathrm{CO}$.

(3) The amount of Pt loading affects the oxygen storage and release rates in the ceria-zirconia solid solution, and the temperature also affects the oxygen storage rate, but not the oxygen release rate from the ceria-zirconia solid solution.

(4) The OSC measured for the catalyst with a small amount of Pt loading or at low temperature is apparently lower than the maximum OSC of ceria-zirconia solid solution under the condition used in this study. This results from the restricted oxygen release process at a temperature more than $250^{\circ} \mathrm{C}$, and the restricted oxygen storage process at a temperature less than $250^{\circ} \mathrm{C}$, in which oxygen could not be completely released within $5 \mathrm{~min}$.

(5) On catalysts with 0.1 mass $\% \mathrm{Pt}$ loading above $200^{\circ} \mathrm{C}$, with 1 mass $\% \mathrm{Pt}$ loading above $100^{\circ} \mathrm{C}$, and 10 mass $\% \mathrm{Pt}$ loading in the entire temperature range, the measured OSC of the ceria-zirconia solid solution reaches to maximum. These OSC data represent the maximum OSCs of the ceria-zirconia solid solution from 50 to $500^{\circ} \mathrm{C}$.

\section{References}

1) Sugiura, M., Materials Integration, Vol. 16, pp. 3-16 (2003).

2) Sugiura, M., Catalysis Surveys from Asia, Vol. 7, pp. 77-87 (2003).

3) Suda, A., Kandori, T., Terao, N., Ukyo, Y., Sobukawa, H. and Sugiura, M., J. Mater. Sci. Lett., Vol. 17, pp. 89-90 (1998).

4) Suda, A., Kandori, T., Ukyo, Y., Sobukawa, H. and Sugiura, 
M., J. Ceram. Soc. Japan, Vol. 108, pp. 473-477 (2000).

5) Trovarelli, A., Zamar, F., Llorca, J., Leitenburg, C., Dolcetti, G. and Kiss, J. T., J. Catal., Vol. 169, pp. 490-502 (1997).

6) Balducci, G., Fornasiero, P., Di Monte, R., Kaspar, J. Meriani, S. and Graziani, M., Catal. Lett., Vol. 33, pp. 193-197 (1995).

7) Fornasiero, P., Kaspar, J. and Graziani, M., J. Catal., Vol. 167, pp. 576-577 (1997).

8) Narula, C. K. and Haack, L. P., J. Phys. Chem., Vol. B103, pp. 3634-3639 (1999).

9) Kaspar, J., Monte, R. D., Fornasiero, R. D., Graziani, M.,
Bradshaw, M. and Norman, C., Topics in Catalysts, Vol. 16/ 17, pp. 83-88 (2001).

10) Suda, A., Sobukawa, H., Kandori, T., Ukyo, Y. and Sugiura, M., J. Ceram. Soc. Japan, Vol. 109, pp. 570-573 (2001).

11) Suda, A., Sobukawa, H., Suzuki, T., Kandori, T., Ukyo, Y. and Sugiura, M., J. Ceram. Soc. Japan, Vol. 109, pp. 177-180 (2001).

12) Suda, A., Ukyo, Y., Sobukawa, H. and Sugiura, M., J. Ceram. Soc. Japan, Vol. 110, pp. 126-130 (2002).

13) Hirano, M. and Suda, A., J. Am. Ceram. Soc., Vol. 86, pp. 2209-2211 (2003). 